\title{
Different fractions of human serum glycoproteins bind galectin-1 or galectin-8, and their ratio may provide a refined biomarker for pathophysiological conditions in cancer and inflammatory disease
}

\author{
Michael C Carlsson, Crina I A Balog, Ola Kilsgard, Thomas Hellmark, Omran Bakoush, \\ Mårten Segelmark, Marten Ferno, Hakan Olsson, Johan Malmstrom, \\ Manfred Wuhrer and Hakon Leffler
}

\section{Linköping University Post Print}

N.B.: When citing this work, cite the original article.

Original Publication:

Michael C Carlsson, Crina I A Balog, Ola Kilsgard, Thomas Hellmark, Omran Bakoush, Mårten Segelmark, Marten Ferno, Hakan Olsson, Johan Malmstrom, Manfred Wuhrer and Hakon Leffler, Different fractions of human serum glycoproteins bind galectin-1 or galectin8 , and their ratio may provide a refined biomarker for pathophysiological conditions in cancer and inflammatory disease, 2012, Biochimica et Biophysica Acta - General Subjects, (1820), 9, 1366-1372.

http://dx.doi.org/10.1016/j.bbagen.2012.01.007

Copyright: Elsevier

http://www.elsevier.com/

Postprint available at: Linköping University Electronic Press http://urn.kb.se/resolve?urn=urn:nbn:se:liu:diva-79630 


\title{
Different fractions of human serum glycoproteins bind
} galectin-1 or galectin- 8 , and their ratio may provide a refined biomarker for pathophysiological conditions in cancer and inflammatory disease.

\author{
Michael C Carlsson ${ }^{1}$, Crina I. A. Balog ${ }^{2}$, Ola Kilsgård ${ }^{3}$, Thomas Hellmark ${ }^{4}$, Omran \\ Bakoush $^{4}$, Mårten Segelmark ${ }^{4,5}$, Mårten Fernö ${ }^{6}$, Håkan Olsson ${ }^{6}$, Johan Malmström³ \\ Manfred Wuhrer ${ }^{2}$ and Hakon Leffler ${ }^{1,7}$
}

\begin{abstract}
${ }^{1}$ Section MIG (Microbiology, Immunology, Glycobiology), Department of Laboratory Medicine, Lund University, Lund, Sweden, ${ }^{2}$ Biomolecular Mass Spectrometry Unit, Department of Parasitology, Leiden University Medical Center, Leiden, The Netherlands, ${ }^{3}$ Department of Immunotechnology, Lund University, Lund, Sweden, ${ }^{4}$ Department of Nephrology, Lund University Hospital, Lund, Sweden. ${ }^{5}$ Department of Medicine and Health, Linköping University, Sweden. ${ }^{6}$ Department of Oncology, Lund University Hospital, Lund, Sweden, ${ }^{7}$ Department of Clinical Immunology and Transfusion Medicine, Skåne University Hospital, SUS, Lund, Sweden.
\end{abstract}

Address correspondence and reprint requests to Michael Carlsson or Hakon Leffler, Department of Laboratory Medicine, Section MIG (Microbiology, Immunology, Glycobiology), Sölvegatan 23, S22362 Lund, Sweden, Tel.: +46-46-173273, Fax: +46-46-137468. Email: michael.carlsson@med.lu.se or hakon.leffler@med.lu.se..

Abbreviations: CRD, carbohydrate recognition domain; Galectin-8N, N-terminal CRD of galectin-8; IgAN, IgA-nephritis 
Carlsson et al., page 2

\section{Abstract}

Background: Changes in glycosylation of serum proteins are common, and various glycoforms are being explored as biomarkers in cancer and inflammation. We recently showed that glycoforms detected by endogenous galectins not only provide potential biomarkers, but also have different function when they encounter galectins in tissue cells. Now we have explored the use of a combination of two galectins with different specificity, to further increase biomarker sensitivity and specificity.

Methods: Sera from 14 women with metastatic breast cancer, 12 healthy controls, 14 patients with $\operatorname{IgA}$-nephritis (IgAN), and 12 patients with other glomerulonephritis were fractionated by affinity chromatography on immobilized human galectin- 1 or galectin- $8 \mathrm{~N}$, and the protein amounts of the bound and unbound fractions for each galectin were determined.

Results: Each galectin bound largely different fractions of the serum glycoproteins, including different glycoforms of haptoglobin. In the cancer sera, the level of galectin-1 bound glycoproteins was higher and galectin- $8 \mathrm{~N}$ bound glycoproteins lower compared to the other patients groups, whereas in IgAN sera the level of galectin- $8 \mathrm{~N}$ bound glycoproteins were higher.

Conclusion: The ratio of galectin-1 bound/galectin-8N bound glycoproteins showed high discriminatory power between cancer patients and healthy, with AUC of 0.98 in ROC analysis, and thus provides an interesting novel cancer biomarker candidate.

General significance: The galectin-binding ability of a glycoprotein is not only a promising biomarker candidate but may also have a specific function when the glycoprotein encounters the galectin in tissue cells, and thus be related to the pathophysiological state of the patient. 
Carlsson et al., page 3

Keywords: Galectin-1, Galectin-8, biomarkers, cancer, inflammation, IgA-nephropathy, serum glycoprotein, glycoform

\section{Introduction}

Since it was discovered in 1969 that cancer glycans differ from glycans on healthy cells [1], efforts have been made to try to understand the underlying molecular mechanism in order to improve diagnostics and treatment. Today, glycosylation changes are considered a universal feature of tumour progression and malignancy. This alteration is due to alterations in cellular pathways probably early in cancer development [2]. Common modifications of cellular glycosylation in cancer include an increase in $\beta-1,6-$ GlcNAc branching, increased numbers of $\mathrm{sLe}^{\mathrm{x}}$, sialyl-Lewis ${ }^{\mathrm{a}}\left(\mathrm{sLe}^{\mathrm{a}}\right), \mathrm{T}$ and $\mathrm{Tn}$ antigens and increased sialylation of $N$-linked glycans [36]. These tumour-associated carbohydrate antigens are central players in cancer progression, and are involved in processes such as cell detachment, proliferation, metastasis, invasion and angiogenesis [7].

In the acute phase response during inflammation, synthesis of certain acute phase proteins in the hepatocytes is upregulated, many of which are glycoproteins. In addition to the increased serum levels, alterations of the glycans of these acute phase glycoproteins also occur over time [8]. Inflammation is considered to be the seventh hallmark of cancer [9] and one common denominator is the altered glycosylation of plasma proteins. While some features are seen both in cancer and inflammation such as increased branching of N-glycans and increased expression of $\mathrm{sLe}^{\mathrm{x}}$ epitopes, other features still remain cancer specific $[2,8]$.

Galectins are a family of small animal proteins that bind specific carbohydrate chains containing $\beta$-galactosides, such as $\mathrm{N}$-acetyllactosamine (LacNAc) commonly found in glycoproteins [10-11], and hence, have the potential to "read" the changes of glycosylation in 
Carlsson et al., page 4

cancer and inflammation described above. Galectins have a wide range of proposed biological roles in cancer, inflammation and immunity [12-14]. At the cellular level they are emerging as key regulators of intracellular trafficking of cellular glycoproteins, with consequences for cellular function e.g in cancer, as well as other pathophysiological conditions [15-16].

While all members of the galectin family bind $\beta$-galactosides they show differences in affinity for longer saccharides and intact glycoproteins, their so called fine specificity [11]. Consequently, galectin-1 and galectin- 8 bind different partially overlapping sets of human serum glycoproteins [10, 17-18]. Previously we found that galectin-1 binds on average almost twice as much glycoprotein, mainly haptoglobin, in sera from patients with metastatic breast cancer compared to healthy individuals [17]. Galectin-1 binds terminal LacNAc-residues and also those carrying 2-3 sialic acid equally well, but the tolerance for 2-3 sialylation is required for its binding to serum glycoproteins $[17,19]$. The galectin-1 bound haptoglobin has different glycosylation (N-linked glycans with less terminal sialic acids, and increased proportion of an additional antenna), and has a different function (altered trafficking after uptake in macrophages) [17]. In another study we found that the N-terminal carbohydrate recognition domain $(\mathrm{CRD})^{1}$ of galectin-8 $\quad$ (galectin- $\left.8 \mathrm{~N}\right)$ binds significantly more glycoproteins, including haptoglobin, in sera of patients with $\operatorname{IgA-nephritis~(IgAN)~compared~}$ to patients with other forms of kidney disease and healthy subjects [18]. Galectin-8N has a strong preference for 2-3 sialylated galactosides [20-21], and its binding of serum glycoproteins requires the presence of 2-3 sialic acid [18], in contrast to the case of galectin-1, suggesting a different binding site.

Here we show that galectin-1 and -8 bind mainly different glycoforms of serum glycoproteins, including different fractions of haptoglobin. Sera from metastatic breast cancer patients contain increased levels of glycoforms that bind galectin-1 but decreased levels that bind galectin- $8 \mathrm{~N}$, whereas sera from patients with a chronic inflammatory condition such as 
Carlsson et al., page 5

IgA nephritis display an opposite profile. As a result, the ratio of galectin-1-bound/galectin-8bound serum glycoproteins provides strong biomarker to segregate the cancer patients from the other groups.

\section{Material and methods}

\subsection{Patient samples}

Cancer sera Human serum samples from 14 female metastatic breast cancer patients and 12 age matched healthy female volunteers (Indicated by C and H in Table S1) were used [17], under ethical permit to authors $\mathrm{HO}$ and MF and approval from the Ethical Review Board at Lund University (Now Regional Ethical Review Board Lund, http://www.epn.se/lund/omnaemnden.aspx). Written informed consent was obtained from all participants.

IgAN sera Serum samples from 14 IgAN patients and 12 patient with other forms of glomerulonephritis (selected as the first non IgAN sample in the biobank taken after the respective IgAN sample) were used (Indicated by P and K in Table S1) [18]. The patients and the controls in this study were all participants in a long-term prospective study of glomerular diseases conducted at the Department of Nephrology, Lund University Hospital, Sweden. Serum samples were taken at time of kidney biopsy. Presenting symptoms were most often hematuria. After approval by the ethical committee at Lund University (LU 47-02) we obtained written informed consent from patients with biopsy proven IgAN, diagnosed between February 1992 and November 2003. The morphological diagnoses were established by evaluation of representative percutaneous renal biopsy specimens by both light microscopy and direct immunofluorescence. The diagnosis of IgAN was based on the finding of IgA as the dominant or co-dominant immunoglobulin in a mesangial distribution pattern. 
Carlsson et al., page 6

All samples were collected and stored as previously described [10]. All information and data was handled confidentially, and evaluation of information linked to patients was carried out in accordance with the Swedish Personal Data Act (Personuppgiftslagen).

\subsection{Production of recombinant galectins}

The recombinant galectins were produced in E. coli BL21 Star and purified by chromatography on lactosyl-Sepharose as previously described [10]. The less oxidation sensitive galectin-1 mutant C3S was used as characterized and described [17, 22].

\subsection{Galectin affinity chromatography}

Sera and haptoglobin (pooled from human plasma, Sigma-Aldrich) were analyzed on affinity columns with immobilized galectins as described by Cederfur et al. [10]. One serum from a cancer patient and one serum from an IgAN patient in addition to $2 \mathrm{mg}$ of haptoglobin were subjected to a two step separation. The unbound fraction of one galectin was rechromatographed on the other. There was no evidence that the column binding capacity was exceeded, since when haptoglobin flow through fractions were rechromatographed on the same galectin, no additional glycoproteins bound.

\subsection{Protein identification}

Serum ligands were analyzed by one-dimensional 4-20\% SDS-PAGE as described previously [10] and four samples; galectin-1 and galectin-8 bound fractions from two cancer patients (C3 and C8) were analyzed by LC-MS/MS of pooled tryptic peptides to identify major protein components and estimate their relative abundance as described in [18]. 
Carlsson et al., page 7

\subsection{Glycan analysis}

\subsubsection{PNgaseF release}

Lactose was removed from galectin- $8 \mathrm{~N}$ by ultrafiltration performing 3 washes with PBS (10KDa Centrifugal Concentrators; Pall, Port Washington, NY). SDS was added to the samples to final concentrations of $1.3 \%(\mathrm{w} / \mathrm{v})$. Samples were heated for $10 \mathrm{~min}$ at $60^{\circ} \mathrm{C}$ and then put on ice. NP-40 was added to the samples to a final concentration of $1.5 \%$. Six mU of PNGase F were added to each sample followed by $24 \mathrm{~h}$ incubation at $37^{\circ} \mathrm{C}$. Subsequently, another $2 \mathrm{mU}$ of PNGase $\mathrm{F}$ were added to each sample, followed by overnight incubation at $37^{\circ} \mathrm{C}$. The PNGase F released glycans were purified by C18-RP-SPE (flow-through) and graphitized carbon SPE (retentate). The C18-RP-cartridges were preconditioned with $5 \mathrm{ml}$ of $\mathrm{ACN}, 5 \mathrm{ml}$ of water/ACN (40/60, by vol), and equilibrated with $5 \mathrm{ml}$ of water. The samples were applied to the cartridges followed by washes with $3 \mathrm{ml}$ of water/ACN (90/10, by vol) and $3 \mathrm{ml}$ of water. The combined flow-through and the wash fractions, containing the released glycans, were further purified by graphitized carbon SPE. For this purpose, the cartridges were preconditioned with $5 \mathrm{ml}$ of ACN, $5 \mathrm{ml}$ of water/ACN (50/50, containing $0.1 \% \mathrm{TFA}$ ), and equilibrated with $10 \mathrm{ml}$ of water. After applying the samples, the cartridges were washed with $10 \mathrm{ml}$ of water and the glycans were eluted with $5 \mathrm{ml}$ of water/ACN (50/50, containing $0.1 \%$ TFA). The eluate containing the purified glycans was dried by vacuum centrifugation.

\subsubsection{Glycan labeling and purification}

For 2-aminobenzoic acid (AA) labeling, the dried, purified glycan samples were dissolved in $50 \mu \mathrm{l}$ water and mixed with $25 \mu \mathrm{l}$ of a freshly prepared label solution $(48 \mathrm{mg} / \mathrm{ml} \mathrm{AA}$ in DMSO containing $15 \%$ glacial acetic acid)(29). Twenty-five $\mu$ l aliquots of freshly prepared reducing agent solution (1 M 2-picoline borane in DMSO) were added, followed by 10 min of 
Carlsson et al., page 8

shaking and incubation at $65^{\circ} \mathrm{C}$ for $2 \mathrm{~h}$. The reaction mixture was allowed to cool down to room temperature.

After labeling, the glycans were purified using graphitized carbon SPE. To this purpose, the cartridges were preconditioned with $5 \mathrm{ml}$ of $\mathrm{ACN}, 5 \mathrm{ml}$ of water/ACN (50/50, containing $0.1 \%$ TFA), and equilibrated with $10 \mathrm{ml}$ of water. The samples were applied, followed by a wash with $10 \mathrm{ml}$ of water. Glycans were eluted with $5 \mathrm{ml}$ of water/ACN (50/50, containing $0.1 \%$ TFA). ACN was removed by vacuum centrifugation, and the samples were freeze-dried and re-dissolved in $20 \mu \mathrm{l}$ water for further analysis by MALDI-FTICR-MS.

\subsubsection{MALDI-FTICR-MS}

Five $\mu$ of each sample were desalted using a $\mathrm{C}_{18}$ ZipTip $^{\mathrm{TM}}$ (Millipore, Billerica, MA) following the manufacturer's instruction. AA-labeled-glycans were eluted with $1.5 \mu 1$ of DHB $(10 \mathrm{mg} / \mathrm{ml}$ in 50:50, ACN:water containing $0.1 \%$ TFA) directly onto a stainless steel MALDI target plate and allowed to dry. MALDI-FTICR experiments were performed on a 15 tesla solariX ${ }^{\mathrm{TM}}$ FTICR mass spectrometer (Bruker Daltonics, Billerica, MA) equipped with a novel CombiSource. The MALDI-FTICR system was controlled by Compass solariXcontrol software and equipped with a Bruker Smartbeam- II ${ }^{\mathrm{TM}}$ laser system that operated at a frequency of $200 \mathrm{~Hz}$. Each mass spectrum was obtained from 30 scans of 150 laser shots using $512 \mathrm{~K}$ data points. Typically, the target plate offset was $-100 \mathrm{~V}$ with the deflector plate set at $-260 \mathrm{~V}$. The ion funnels operated at $-120 \mathrm{~V}$ with the skimmer at $-15 \mathrm{~V}$. The trapping potentials were set at -0.40 and $-0.5 \mathrm{~V}$ and the analyzer entrance was maintained at $4 \mathrm{~V}$. The required excitation power was 22\%. DataAnalysis Software 4.0 SP 3 (Bruker Daltonics) was used for the visualization and the calibration of the spectra. The spectra were internally calibrated using six N-glycans. 
Carlsson et al., page 9

\subsection{Haptoglobin ELISA}

Haptoglobin was quantitated as described previously in unseparated sera and galectin-1 and galectin- 8 bound fractions for 14 cancer sera, 12 healthy sera, 13 IgAN sera and 11 sera from patients with other forms of glomerulonephritis [17].

\subsection{Statistical analysis and ROC-plots}

All pair wise comparisons between the cancer and control sera and between IgAN sera and patients with other forms of glomerulonephritis were done by a two tailed unpaired t-test, and receiver operating characteristic (ROC) curves were constructed using the Prism software (Graph Pad Software Inc., San Diego, CA).

\section{Results}

\subsection{Galectin-1 and -8 bind mainly different fractions of serum glycoproteins.}

Sera from patients with metastatic breast cancer, IgAN, other kidney disease and healthy controls were fractionated by affinity chromatography on immobilized galectin-1 and galectin-8N. Galectin-1 bound mainly $\alpha$-2-macroglobulin and haptoglobin, and in most cases also IgM in serum [10, 17]; galectin- $8 \mathrm{~N}$ also bound $\alpha$-2-macroglobulin and haptoglobin, but $\operatorname{IgA}$ instead of $\operatorname{IgM}$ and in addition some other glycoproteins $[10,18]$ as exemplified for two sera in Fig. 1A. The concentration of galectin-1 bound glycoproteins in cancer sera was significantly higher compared to other sera, whereas galectin- $8 \mathrm{~N}$ bound significantly less, as exemplified for one serum of each category in Fig. 1B.

To further analyse the relationship between galectin-1 and galectin- $8 \mathrm{~N}$ bound serum glycoproteins, sera were first fractionated on one galectin and then the unbound fraction was 
Carlsson et al., page 10

fractionated on the other as described in Fig. 1C and D. It appears that in general different fractions of the serum glycoproteins bind to each galectins, while only a smaller fraction may bind to both galectins. For example, in a cancer serum $3.6 \mathrm{mg} / \mathrm{ml}$ glycoproteins bound galectin-1, when analysed directly, and almost the same amount $(3.2 \mathrm{mg} / \mathrm{ml})$ if the serum had first passed through a galectin- $8 \mathrm{~N}$ column to remove the galectin- $8 \mathrm{~N}$ bound glycoproteins. Conversely, in another serum $5.9 \mathrm{mg} / \mathrm{ml}$ bound galectin- $8 \mathrm{~N}$ if analysed directly and 5.5 $\mathrm{mg} / \mathrm{ml}$ if the galectin-1 bound glycoproteins had first been removed.

A deeper proteomics characterization of the galectin bound fractions from two cancer sera (C3 and C8 in Table S1) by LC-MS/MS of pooled tryptic peptides (Table S2) was in general agreement with the analysis by SDS-PAGE described above, but with interesting additional sample variation in haptoglobin levels. The level of haptoglobin was dramatically different between the galectin-1 bound fractions with very high in $\mathrm{C} 8$ and very low in $\mathrm{C} 3$, whereas the galectin- 8 bound fractions from the same samples contained similar moderate levels of haptoglobin. This provides further evidence that galectin-1 and -8 bind different forms of haptoglobin. In addition, both galectin-1 bound fractions contained $\alpha--2-$ macroglobulin and $\operatorname{IgM}$ as main components, and both galectin- 8 bound fractions contained $\alpha--2$-macroglobulin and $\operatorname{IgA}$ as main components and a range of minor components as described before.

To further analyse the differentially bound haptoglobin forms, $2 \mathrm{mg}$ of purified human haptoglobin was fractionated using a two-step separation (Fig. S1) as described for whole serum above. Galectin-1 bound approximately $0.6 \mathrm{mg}(30 \%)$ and galectin- $8 \mathrm{~N}$ about $0.4 \mathrm{mg}$ $(20 \%)$ of the haptoglobin which is in agreement with our previous findings [17] [18]. Of the galectin-1 unbound fraction only $0.1 \mathrm{mg}$ bound galectin- $8 \mathrm{~N}$ while in the galectin- $8 \mathrm{~N}$ unbound fraction $0.3 \mathrm{mg}$ was able to bind galectin-1 when rechromatographed. Hence, galectin-1 and - 
Carlsson et al., page 11

8 bind different fractions of purified human haptoglobin and although the separation is not as distinct, it is consistent with our findings for total serum above.

N-glycans were released from the different haptoglobin fractions of Fig. S1 and analyzed by mass spectrometry. The galectin-1 bound haptoglobin was enriched in triantennary N-glycans compared to non-bound and total haptoglobin (not shown) in agreement with our previous findings [17]. In contrast, the galectin- $8 \mathrm{~N}$ bound haptoglobin had a similar $\mathrm{N}$-glycan profile, with no significant difference, compared to the galectin- $8 \mathrm{~N}$ unbound or total haptoglobin (Fig. S2). This provides additional evidence that galectin-1 and 8 bind different glycoforms of haptoglobin.

\subsection{Increase of galectin-1 and decrease of Galectin-8N binding glycoproteins in cancer sera.}

We previously showed that galectin-1 binds increased amounts of glycoproteins in sera from metastatic breast cancer patients and that galectin- $8 \mathrm{~N}$ binds increased amounts of glycoproteins from sera of IgAN patients compared. In the current study we performed a reverse analysis by quantitated the amount of galectin- $8 \mathrm{~N}$ bound glycoproteins in cancer sera and the amounts of galectin-1 bound glycoproteins in IgAN sera.

The concentration of galectin-8N-bound glycoproteins was significantly lower in sera from cancer patients (average $1.3 \mathrm{mg} / \mathrm{ml}$ serum, range $0.3-2.8$ ) compared to healthy (average 2.9 $\mathrm{mg} / \mathrm{ml}$, range 1.5 - 5.2) and the other patient groups; sera from IgAN patients showed the highest concentration, almost three times as high as for the cancer patients (average, 3.8 $\mathrm{mg} / \mathrm{ml}$, range $1.6-5.9)$ (Fig. 2A).

The concentration of galectin-1 bound proteins was instead significantly lower in sera from IgAN patients (average $0.8 \mathrm{mg} / \mathrm{ml}$, range $0.3-1.5$ ), compared to healthy (average 1.1, range $0.8-2.2$ ), and patients with other forms of glomerulonephritis (average 1.2, range $0.5-1.7$ ), 
Carlsson et al., page 12

whereas the yield from the cancer patient sera was significantly higher with an average of 2.2 mg per ml serum (range 1.1 - 3.9) (Fig. 2A). The patient metadata are summarized in Table S1.

\subsection{Galectin-1 and galectin-8N detect different disease related glycoforms of haptoglobin}

Since haptoglobin is a major glycoprotein bound by both galectin-1 and galectin- $8 \mathrm{~N}$, we measured its quantity in total sera and in the galectin-bound fractions (Fig. 2B), and from this calculated the $\%$ of haptoglobin bound to each galectin (Fig. 2C). For healthy sera, galectin-1 bound slightly less haptoglobin (average $0.43 \mathrm{mg} / \mathrm{ml}, 34 \%$ ) compared to galectin- $8 \mathrm{~N}$ (average $0.58 \mathrm{mg} / \mathrm{ml}, 47 \%$ ) (Fig.2B). In sera from cancer patients, however, galectin-1 bound increased levels of haptoglobin (average $0.84 \mathrm{mg} / \mathrm{ml}$, (52\%), while galectin- $8 \mathrm{~N}$ bound decreased levels (average $0.24 \mathrm{mg} / \mathrm{ml}, 16 \%$ ). Also noticeable was the significant increase of galectin- $8 \mathrm{~N}$ bound haptoglobin in IgAN patients (64\%) compared to patients with other forms of glomerulonephritis (42\%) (Fig. 2C).

\subsection{Significantly improved biomarker using Galectin-1/Galectin-8N binding ratios.}

Since the two galectins appear to recognize different disease associated glycoforms we wanted to explore the possibility of using the combination of these two galectins to refine the method in finding functional relevant glycoforms as biomarkers. Thus, the ratio of the yields (galectin-1-bound/galectin-8N-bound) provides a significantly improved discrimination with average 2.33 (range $0.7-4.5$ ) for the cancer patients and average $<0.6$ (range $0.2-0.9$ ) for the other groups, and an area under the curve (AUC) of 0.98 in a ROC-plot (Fig. 3A). There was also a clear but less significant separation between IgAN and patients with other forms of glomerulonephritis, 0.23 (range $0.1-0.6$ ) versus 0.63 (range $0.2-1.1)(\mathrm{AUC}=0.90)$ (Fig. 3A). The key protein for this discrimination seems to be haptoglobin since the ratio of 
Carlsson et al., page 13

galectin-1/galectin- $8 \mathrm{~N}$ bound haptoglobin shows a similar discrimination between the cancer patients and the other groups $(\mathrm{AUC}=0.98$, Fig. 3B $)$.

\section{Discussion}

Here we provide a practical and sensitive method for detection of some functionally relevant disease associated glycosylation changes of serum glycoproteins. The distinct carbohydrate fine specificities of galectin-1 and $-8 \mathrm{~N}$ permit detection of two largely separate sets of glycoforms. For haptoglobin the differential capturing with the two galectins provides evidence for the variation of its glycoform pattern in different direction with different diseases.

Most glycans on human serum glycoproteins do not bind galectins because they either do not contain $\beta$-galactoside (Gal $\beta$ ) residues or Gal $\beta$ residues are capped with NeuAc $\alpha 2-6$ that sterically blocks binding of all galectins [11]. Our previous results showed that galectin-1 binds a specific relatively minor subset of glycans. This can still result in binding of a major fraction of a glycoprotein such as haptoglobin because a monovalent interaction with only one glycan of many (e.g. $>10$ for haptoglobin) suffices to confer binding to galectin-1 [17]. A likely component of galectin-1-binding sites is the carbohydrate sequence NeuAc $\alpha 2-3$ Gal $\beta 1$ 4GlcNAc [17]. In human serum this is typically found in a fraction of tri-and tetranatennary N-glycans, which were indeed enriched in the galectin-1 bound haptoglobin fraction [17]. Here we show that the galectin- $8 \mathrm{~N}$ bound fraction of both whole serum glycoproteins and of purified haptoglobin contain different glycoforms, and there was no enrichment of tri- or tetraantennary N-glycans. The binding of galectin- $8 \mathrm{~N}$ requires the presence of NeuAca2-3 and one likely binding site is the O-linked glycan NeuAc $22-3 \mathrm{Gal} \beta 1-3 \mathrm{GalNAc}$ as found in IgA [18]. O-glycans have not been reported in e.g. haptoglobin so far, but this does not rule out 
Carlsson et al., page 14

that they exist in a fraction of it. Alternatively, galectin-8N binds NeuAca2-3Gal $31-3 \mathrm{GlcNAc}$, which it also prefers over the galectin-1 binding NeuAc $\alpha 2-3$ Galß1-4GlcNAc [20], and which may occur in N-glycans. Hence, galectin-1 and $-8 \mathrm{~N}$ may be detecting the balance between two different glycosylation features, which in turn would be determined by the activity of glycosyltransferases typical for the cell making the glycoprotein and further regulated by surrounding pathophysiological conditions. It should be emphasised that there is not a total discrimination between galectin-1 and galectin- 8 binding glycoforms since there is a clear overlap in binding of haptoglobin, meaning that one molecule may carry both a galectin-1 and $-8 \mathrm{~N}$-binding structure. This is less apparent when analyzing the total serum protein population, given that a number of glycoproteins are galectin-8N specific (e.g. IgA, hemopexin) while IgM only bind galectin-1.

In inflammation, serum concentrations of acute phase proteins such as haptoglobin increase (positive acute-phase proteins). This is mainly due to changes in their production by hepatocytes triggered by cytokines secreted by macrophages and monocytes at inflammatory sites [23]. Elevated levels of acute phase proteins have also been found in cancer [24], in which the hepatocyte stimulating cytokines are most likely produced by the tumour microenvironment [25]. However, the source of acute phase proteins might also be peripheral; both cancer cells and non-hepatic normal cells, e.g. in kidney produce haptoglobin [26]. Hence, the different glycoforms of haptoglobin found in this study for cancer and IgAN sera may have different cellular origin, since glycosylation processing is very much cell type specific. They may also be due to induction of different glycosyltransferase activity in the same cell type, e.g. hepatocytes, by factors released under the pathophysiolocal conditions, such as cytokines. As mentioned in the introduction, cancer and inflammation only display partially similar disease associated glycosylation changes. 
Carlsson et al., page 15

The different galectin detected glycoforms may not only serve as biomarkers but also have different biological function when they encounter galectins in vivo. This encounter is not likely to be significant in serum itself where the concentrations of galectins are much lower (< $50 \mathrm{nM})$ [27] than the of the glycoproteins studied here (>5000 nM), but may be of relevance when the serum glycoproteins reach tissue cells where galectin concentration may be high. Thus, we showed that galectin-1 bound and non-bound haptoglobin take different intracellular paths after uptake into alternatively activated macrophages [17]. Galectin-8 evidently recognizes other glycoforms of haptoglobin (and other glycoproteins) that were largely not recognized by galectin-1, and one may speculate that it would be differentially directed after uptake into galectin-8 expressing cells. If so, galectin-8 binding of haptoglobin could represent a distinct intracellular sorting mechanism that alters the functional state of tissue cells in patients with an inflammatory condition such as IgAN compared to cancer patient. In IgAN sera galectin- $8 \mathrm{~N}$ bind more than 60 percent of all serum haptoglobin, while the corresponding percentage in cancer sera is 20 . The numbers are reversed for galectin- 1 . The functional significance of elevated levels of abnormal glycoforms of haptoglobin with increased binding to galectin-1 seen in cancer could influence haptoglobin activities such as angiogenesis [28], as discussed in [17]. If the same concept could be applied on galectin-8N binding of haptoglobin, the intracellular sorting of haptoglobin after endocytosis in inflammation such as IgAN would be widely divergent from its sorting in cancer.

\section{Conclusions}

This study demonstrates that galectin- 1 and galectin- 8 recognize different disease-associated glycoforms of serum glycoproteins. The ratio of galectin-1-bound/galectin-8-bound serum glycoproteins provides a cancer biomarker, with remarkable sensitivity and specificity, unbiased from inflammation. Moreover, glycoforms bound by these endogenous galectins 
Carlsson et al., page 16

also have different function compared to non-bound glycoforms, such as the previously shown galectin-1 related targeting of haptoglobin inside tissue cells. Thus, galectins detect glycoforms that are useful disease related biomarkers, but also have different function that may be related to the pathophysiology.

\section{Acknowledgements}

We thank Barbro Kahl-Knutson, Carolien Koeleman and Agnes Hipgrave Ederveen for excellent technical support. The work was supported by grants from the Swedish Research Council (Vetenskapsrådet) and Region Skåne to HL, from the Swedish Cancer Society, Lund University Hospital Foundation and Region Skåne to MF and HO, from the Swedish Research Council (project 2008-3356) and the Swedish Foundation for Swedish Research (FFL4) to JM, and the from the Swedish Research Council, Lund University Hospital funds, and the Crafoord Foundation to TH and MS, and from Swedish Healthcare System (ALF) to OB, TH and MS,. 
Carlsson et al., page 17

\section{Figure legends}

Figure 1. Affinity chromatography of cancer, IgAN and healthy sera on immobilized human galectin-1 and galectin-8N. (A) SDS-PAGE (4-20\% stained with Coomassie) of bound glycoproteins from affinity chromatography of IgAN patient serum on immobilized galectin-8N and cancer patient sera on immobilized galectin-1. Indicated with lowercase letters are known serum proteins (Molecular weights based on gel mobility are presented in brackets): (a) $\alpha$-2-macroglobulin (163 kDa) (b) inter- $\alpha$-trypsin inhibitor (101 kDa) (c) hemopexin $(55 \mathrm{kDa})$ (d) $\operatorname{IgA}$ heavy chain (53 kDa) (e) $\alpha$-1-antitrypsin (47 kDa) (f) haptoglobin $\beta$-chain (45 kDa) (g) IgA light chain $(25 \mathrm{kDa})(\mathrm{h})$ haptoglobin $\alpha$-chain $(19 \mathrm{k} \mathrm{Da})$ (i) IgM heavy chain $(66 \mathrm{kDa})$. Proteins have previously been identified with Western blot and MALDI-TOF-MS [10]. (B) Exemplified chromatograms and corresponding SDS PAGE gels for one cancer and one IgAN patient serum, separated on galectin- $8 \mathrm{~N}$ and galectin-1. (C) The same cancer and IgAN sera, respectively, as shown in panels A and B were first fractionated on one galectin and then the pooled unbound fractions were fractionated on the other galectin. (D) Table of results from (C) and corresponding fractionation of a healthy serum (not shown).

Figure 2. Quantitation of total protein and haptoglobin in galectin-1 and -8 bound fractions from cancer, healthy, IgAN and glomerulonephritis sera. (A) Yield of galectin$8 \mathrm{~N}$ and galectin-1 binding proteins (sum of protein amount in bound fractions multiplied by 10 to give mg per $\mathrm{ml}$ original serum) for sera from 14 cancer patients, 14 IgAN patients, 12 patient with other forms of glomerulonephritis, and 12 healthy individuals. The average for each group is marked by horizontal lines, significant differences between groups are indicated by p-value summary symbol $(* * *,<0.001 ; * *, 0.001-0.01 ; *, 0.01-0.05)$ using two tailed unpaired t-test. (B) The concentrations of haptoglobin in the galectin- $8 \mathrm{~N}$ and galectin-1 bound 
Carlsson et al., page 18

fractions from same sera as in (A) (except that one IgAN sera and one glomerulonephritis serum are excluded) as determined by direct enzyme-linked immunosorbent assay (ELISA). (C) Percentage of total serum haptoglobin (determined with ELISA) in galectin-8N and galectin-1 bound fractions for the same sera as analyzed in panel (B).

Figure 3. Ratio of galectin-1/galectin-8N bound total proteins and haptoglobin in galectin-1 and -8 bound fractions from cancer, healthy, IgAN and glomerulonephritis sera. (A) Ratio of galectin-1/galectin-8 bound protein from Fig. 2A, and (B) ratio of galectin1 and galectin- 8 bound haptoglobin from Fig. 2B for all patient groups. The averages for each group are marked by horizontal lines. The two bottom graphs in each panel are receiver operating characteristic (ROC) curve analysis of the respective ratio's power to distinguish breast cancer patients from healthy (left) and IgAN patients from patients with other forms of glomerulonephritis (right). The area under the curve (AUC) indicates the discriminatory power of the measured parameter. A value $>0.90$ is considered excellent. 


\section{References}

[1] E. Meezan, H.C. Wu, P.H. Black, P.W. Robbins, Comparative studies on the carbohydrate-containing membrane components of normal and virus-transformed mouse fibroblasts. II. Separation of glycoproteins and glycopeptides by sephadex chromatography, Biochemistry, 8 (1969) 2518-2524.

[2] D.H. Dube, C.R. Bertozzi, Glycans in cancer and inflammation--potential for therapeutics and diagnostics, Nat Rev Drug Discov, 4 (2005) 477-488.

[3] J.W. Dennis, S. Laferte, C. Waghorne, M.L. Breitman, R.S. Kerbel, Beta 1-6 branching of Asn-linked oligosaccharides is directly associated with metastasis, Science, 236 (1987) 582585.

[4] Y. Matsushita, K.R. Cleary, D.M. Ota, S.D. Hoff, T. Irimura, Sialyl-dimeric Lewis-X antigen expressed on mucin-like glycoproteins in colorectal cancer metastases, Lab Invest, 63 (1990) 780-791.

[5] G.F. Springer, T and Tn, general carcinoma autoantigens, Science, 224 (1984) 1198-1206.

[6] Y.J. Kim, A. Varki, Perspectives on the significance of altered glycosylation of glycoproteins in cancer, Glycoconj J, 14 (1997) 569-576.

[7] M.M. Fuster, J.D. Esko, The sweet and sour of cancer: glycans as novel therapeutic targets, Nat Rev Cancer, 5 (2005) 526-542.

[8] J.N. Arnold, R. Saldova, U.M. Hamid, P.M. Rudd, Evaluation of the serum N-linked glycome for the diagnosis of cancer and chronic inflammation, Proteomics, 8 (2008) 32843293.

[9] D. Hanahan, R.A. Weinberg, Hallmarks of cancer: the next generation, Cell, 144 (2011) 646-674.

[10] C. Cederfur, E. Salomonsson, J. Nilsson, A. Halim, C.T. Oberg, G. Larson, U.J. Nilsson, H. Leffler, Different affinity of galectins for human serum glycoproteins: galectin-3 binds many protease inhibitors and acute phase proteins, Glycobiology, 18 (2008) 384-394.

[11] H. Leffler, S. Carlsson, M. Hedlund, Y. Qian, F. Poirier, Introduction to galectins, Glycoconj J, 19 (2004) 433-440.

[12] F.T. Liu, G.A. Rabinovich, Galectins as modulators of tumour progression, Nat Rev Cancer, 5 (2005) 29-41.

[13] F.T. Liu, G.A. Rabinovich, Galectins: regulators of acute and chronic inflammation, Ann N Y Acad Sci, 1183 (2010) 158-182.

[14] G.A. Rabinovich, M.A. Toscano, Turning 'sweet' on immunity: galectin-glycan interactions in immune tolerance and inflammation, Nat Rev Immunol, 9 (2009) 338-352.

[15] K.S. Lau, E.A. Partridge, A. Grigorian, C.I. Silvescu, V.N. Reinhold, M. Demetriou, J.W. Dennis, Complex N-glycan number and degree of branching cooperate to regulate cell proliferation and differentiation, Cell, 129 (2007) 123-134.

[16] D. Delacour, A. Koch, R. Jacob, The role of galectins in protein trafficking, Traffic, 10 (2009) 1405-1413.

[17] M.C. Carlsson, C. Cederfur, V. Schaar, C.I.A. Balog, A. Lepur, F. Touret, E. Salomonsson, A.M. Deelder, M. Fernö, H. Olsson, M. Wuhrer, H. Leffler, Galectin-1-binding glycoforms of haptoglobin with altered intracellular trafficking, and increase in metastatic breast cancer patients., PLoS ONE, 6 (2011) e26560. Epub 2011 Oct 18.

[18] M.C. Carlsson, O. Bakoush, L. Tengroth, O. Kilsgård, J. Malmström, T. Hellmark, M. Segelmark, H. Leffler, Galectin-8 in IgA nephritis: decreased binding of IgA by galectin- 8 affinity chromatography and associated increased binding in non-IgA serum glycoproteins, Journal of Clinical Immunology (2011) Dec 16. [Epub ahead of print]. 
[19] S.R. Stowell, C.M. Arthur, P. Mehta, K.A. Slanina, O. Blixt, H. Leffler, D.F. Smith, R.D. Cummings, Galectin-1, -2, and -3 exhibit differential recognition of sialylated glycans and blood group antigens, J Biol Chem, 283 (2008) 10109-10123.

[20] S. Carlsson, C.T. Oberg, M.C. Carlsson, A. Sundin, U.J. Nilsson, D. Smith, R.D. Cummings, J. Almkvist, A. Karlsson, H. Leffler, Affinity of galectin-8 and its carbohydrate recognition domains for ligands in solution and at the cell surface, Glycobiology, 17 (2007) 663-676.

[21] H. Ideo, T. Matsuzaka, T. Nonaka, A. Seko, K. Yamashita, Galectin-8-N-domain recognition mechanism for sialylated and sulfated glycans, J Biol Chem, 286 (2011) 1134611355.

[22] E. Salomonsson, A. Larumbe, J. Tejler, E. Tullberg, H. Rydberg, A. Sundin, A. Khabut, T. Frejd, Y.D. Lobsanov, J.M. Rini, U.J. Nilsson, H. Leffler, Monovalent interactions of galectin-1, Biochemistry, 49 (2010) 9518-9532.

[23] C. Gabay, I. Kushner, Acute-phase proteins and other systemic responses to inflammation, N Engl J Med, 340 (1999) 448-454.

[24] G.A. Turner, A.W. Skillen, P. Buamah, D. Guthrie, J. Welsh, J. Harrison, A. Kowalski, Relation between raised concentrations of fucose, sialic acid, and acute phase proteins in serum from patients with cancer: choosing suitable serum glycoprotein markers, J Clin Pathol, 38 (1985) 588-592.

[25] G. Tricot, New insights into role of microenvironment in multiple myeloma, Lancet, 355 (2000) 248-250.

[26] M.B. Smeets, J. Fontijn, A. Kavelaars, G. Pasterkamp, D.P. De Kleijn, The acute phase protein haptoglobin is locally expressed in arthritic and oncological tissues, Int J Exp Pathol, 84 (2003) 69-74.

[27] H. Barrow, X. Guo, H.H. Wandall, J.W. Pedersen, B. Fu, Q. Zhao, C. Chen, J.M. Rhodes, L.-G. Yu, Serum Galectin-2, -4, and -8 Are Greatly Increased in Colon and Breast Cancer Patients and Promote Cancer Cell Adhesion to Blood Vascular Endothelium, Clinical Cancer Research, 17 (2011) 7035-7046.

[28] M.C. Cid, D.S. Grant, G.S. Hoffman, R. Auerbach, A.S. Fauci, H.K. Kleinman, Identification of haptoglobin as an angiogenic factor in sera from patients with systemic vasculitis, J Clin Invest, 91 (1993) 977-985.

[29] T. Farrah, E.W. Deutsch, G.S. Omenn, D.S. Campbell, Z. Sun, J.A. Bletz, P. Mallick, J.E. Katz, J. Malmström, R. Ossola, J.D. Watts, B. Lin, H. Zhang, R.L. Moritz, R. Aebersold R. A high-confidence human plasma proteome reference set with estimated concentrations in PeptideAtlas. Mol Cell Proteomics. 2011 Sep;10(9):M110.006353. Epub 2011 Jun 1. 
A

Galectin-8N

Galectin-1

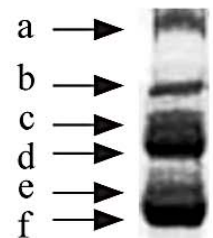

$\mathrm{g} \rightarrow$ wan

$\mathrm{h} \rightarrow$

B

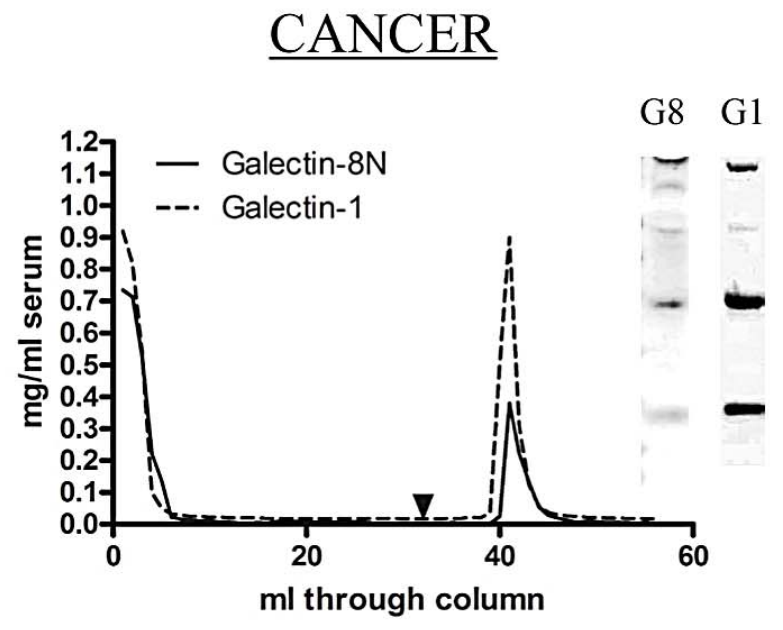

IgAN
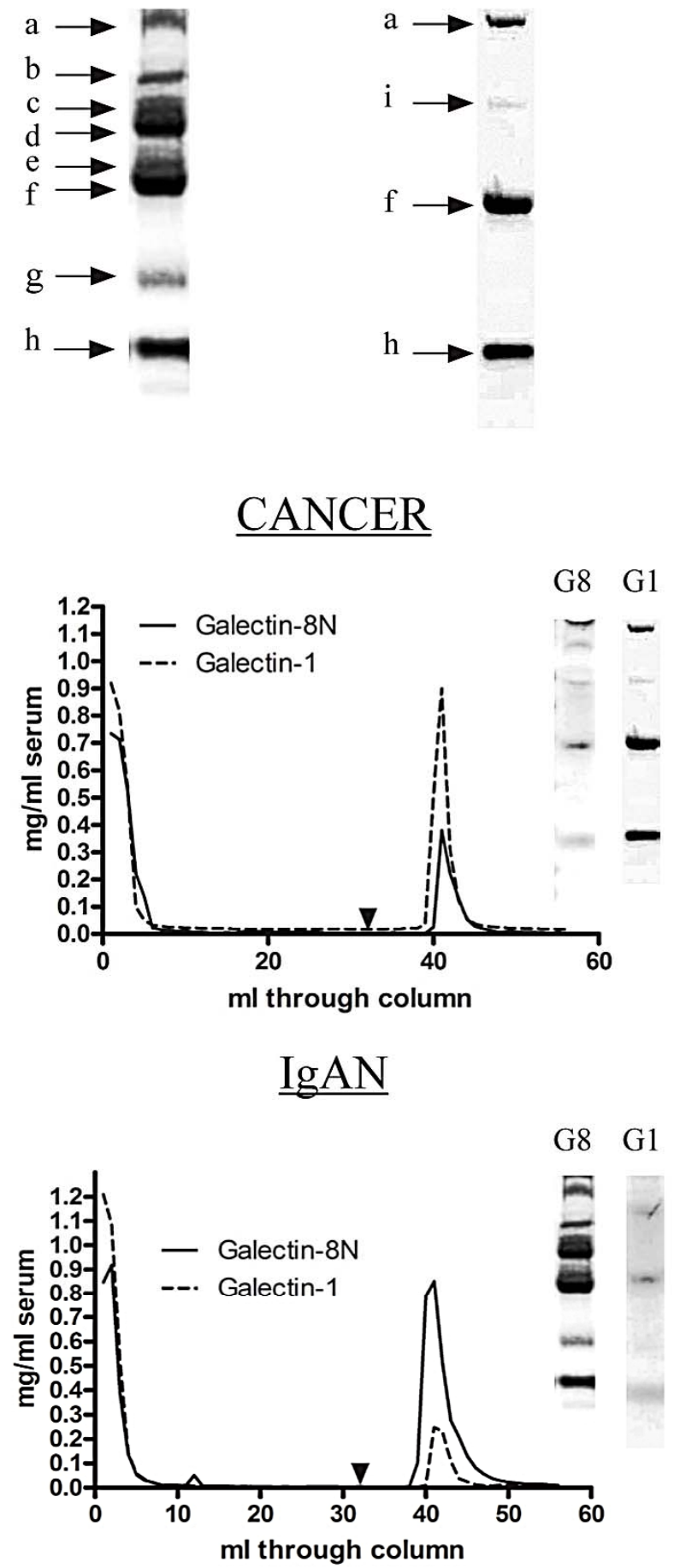

IgAN

CANCER
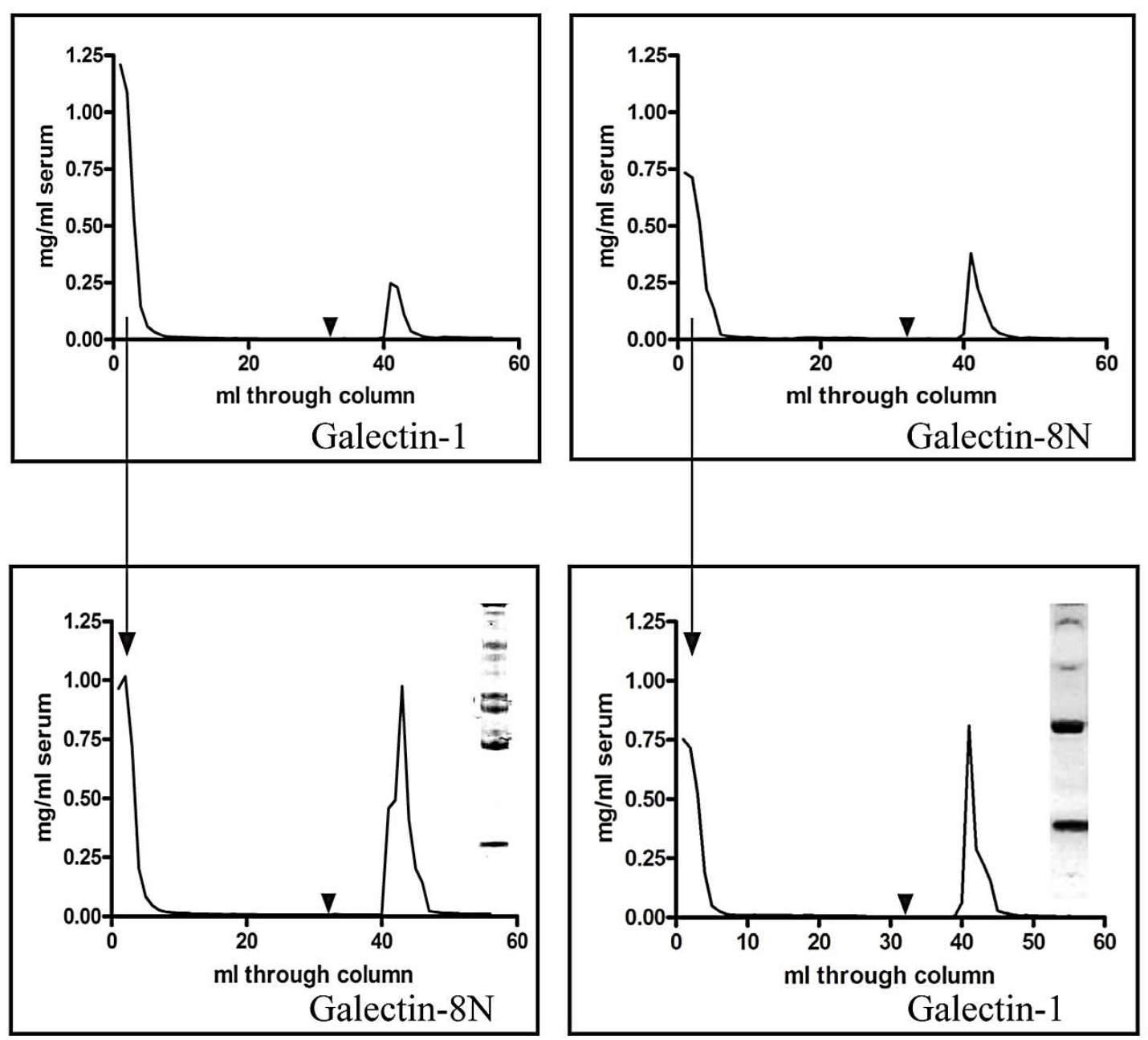

D

\begin{tabular}{|l|c|c|}
\hline \hline Serum sample. & $\begin{array}{l}\text { Galectin-1 binding } \\
\text { (mg/ml serum) }\end{array}$ & $\begin{array}{l}\text { Galectin-8N binding } \\
\text { (mg/ml serum) }\end{array}$ \\
\hline Cancer & 3,6 & 1,7 \\
\hline Cancer Galectin-8N unbound & 3,2 & - \\
\hline IgAN & 1,3 & 5,9 \\
\hline IgAN Galectin-1 unbound & - & 5,5 \\
\hline Healthy & 1,6 & 4,1 \\
\hline Healthy Galectin-8N unbound & 1,2 & - \\
\hline Healthy Galectin-1 unbound & - & 3,2 \\
\hline \hline
\end{tabular}


A

B

Total bound fraction

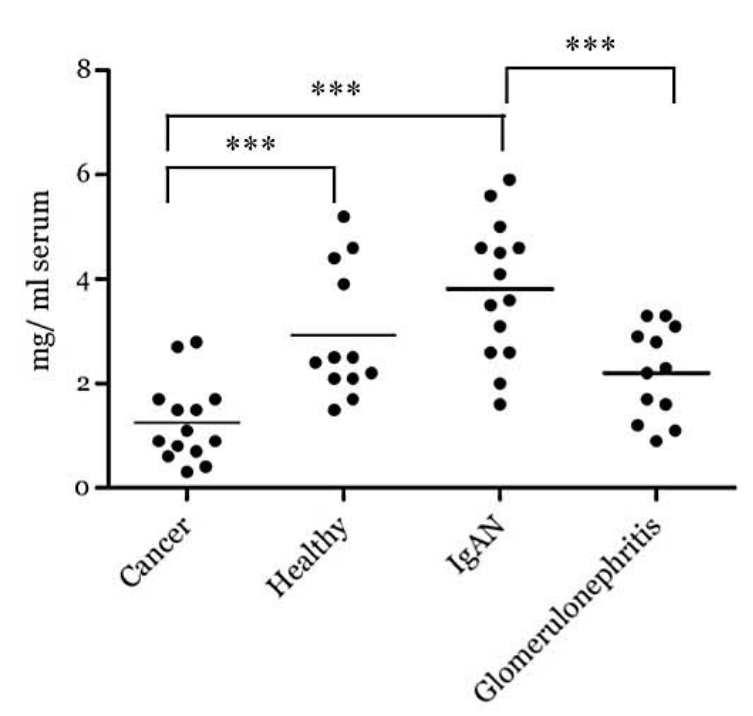

Galectin-1 C3S

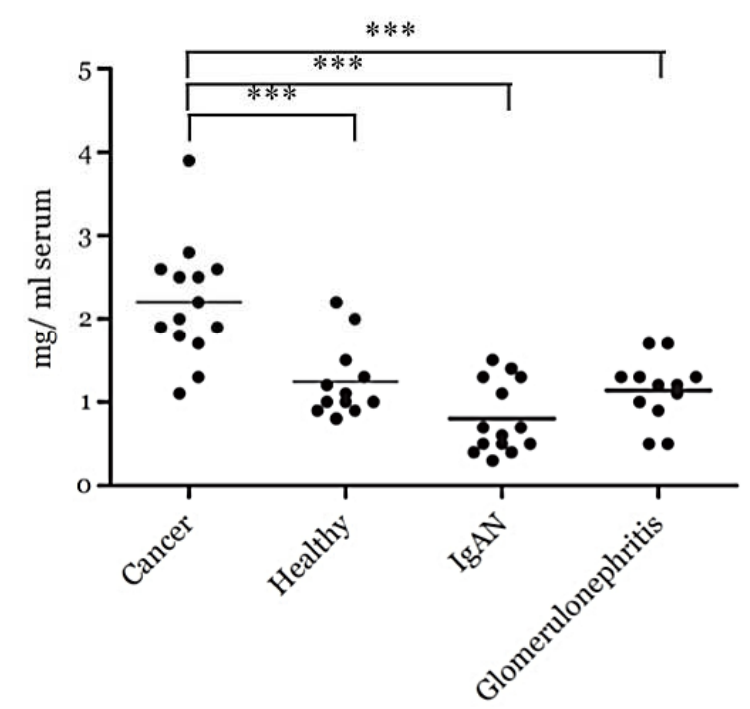

Bound haptoglobin
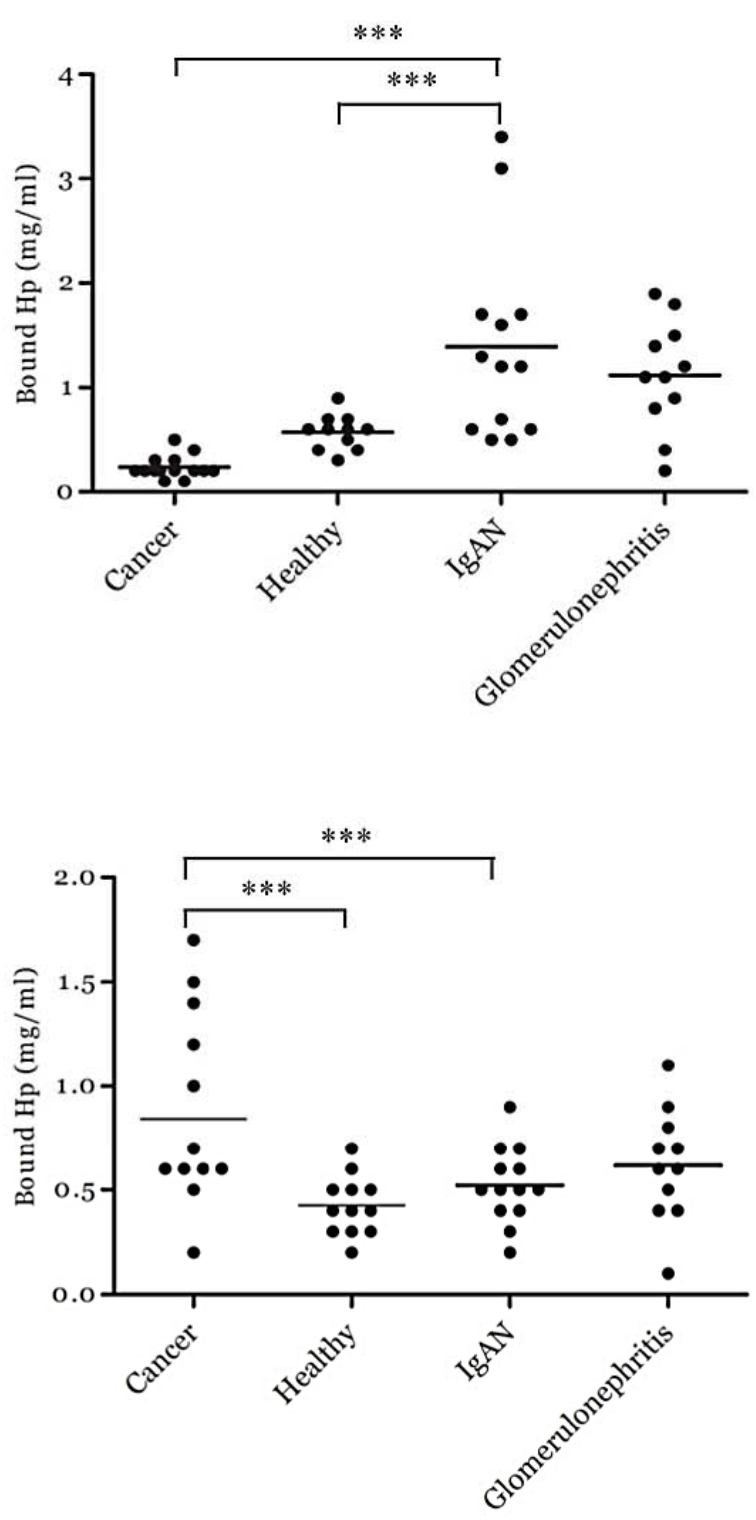

C

Procentage bound haptoglobin

(Bound $\mathrm{Hp} /$ Total serum Hp)
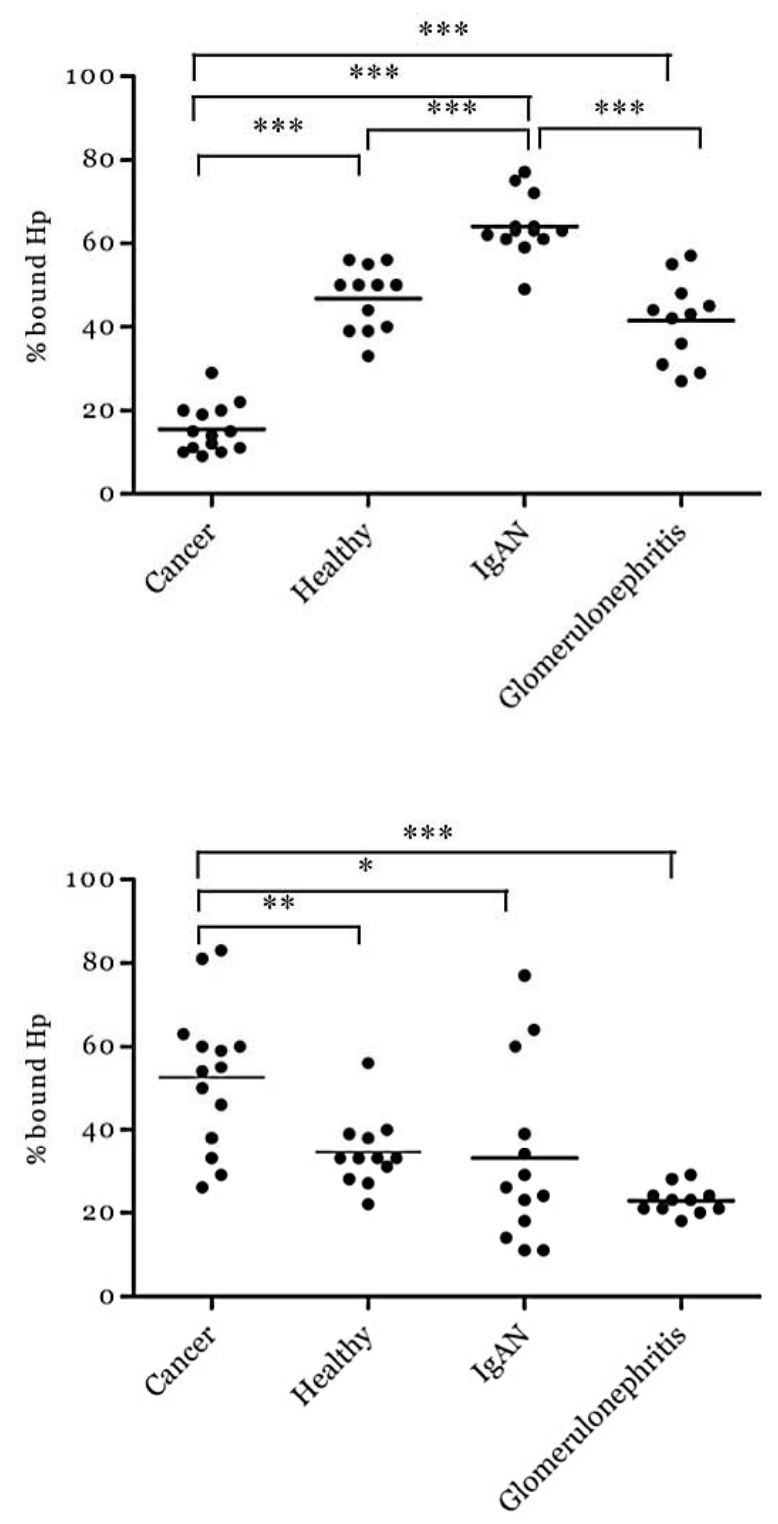
A

Bound total protein
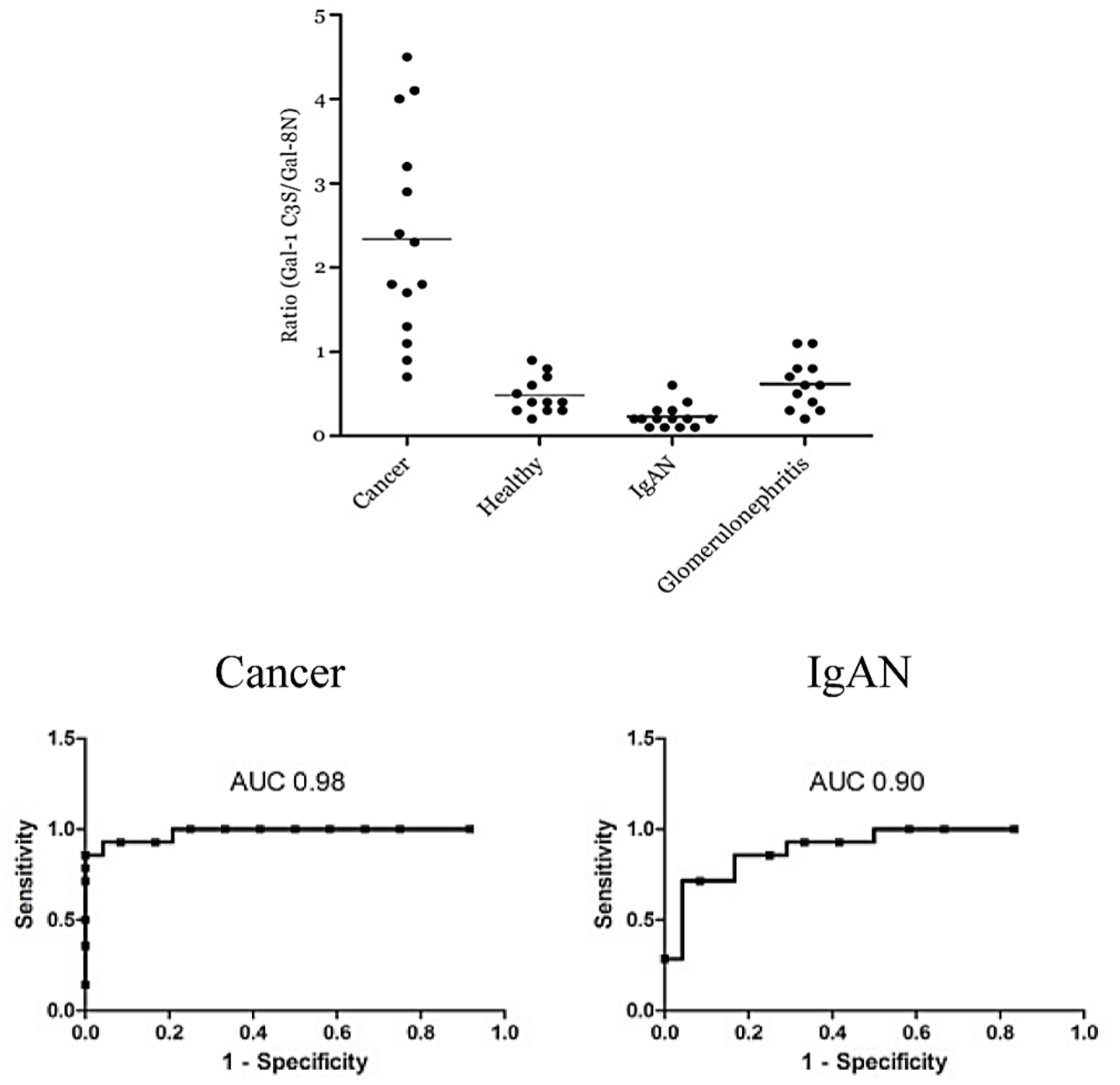

B

Bound Hp
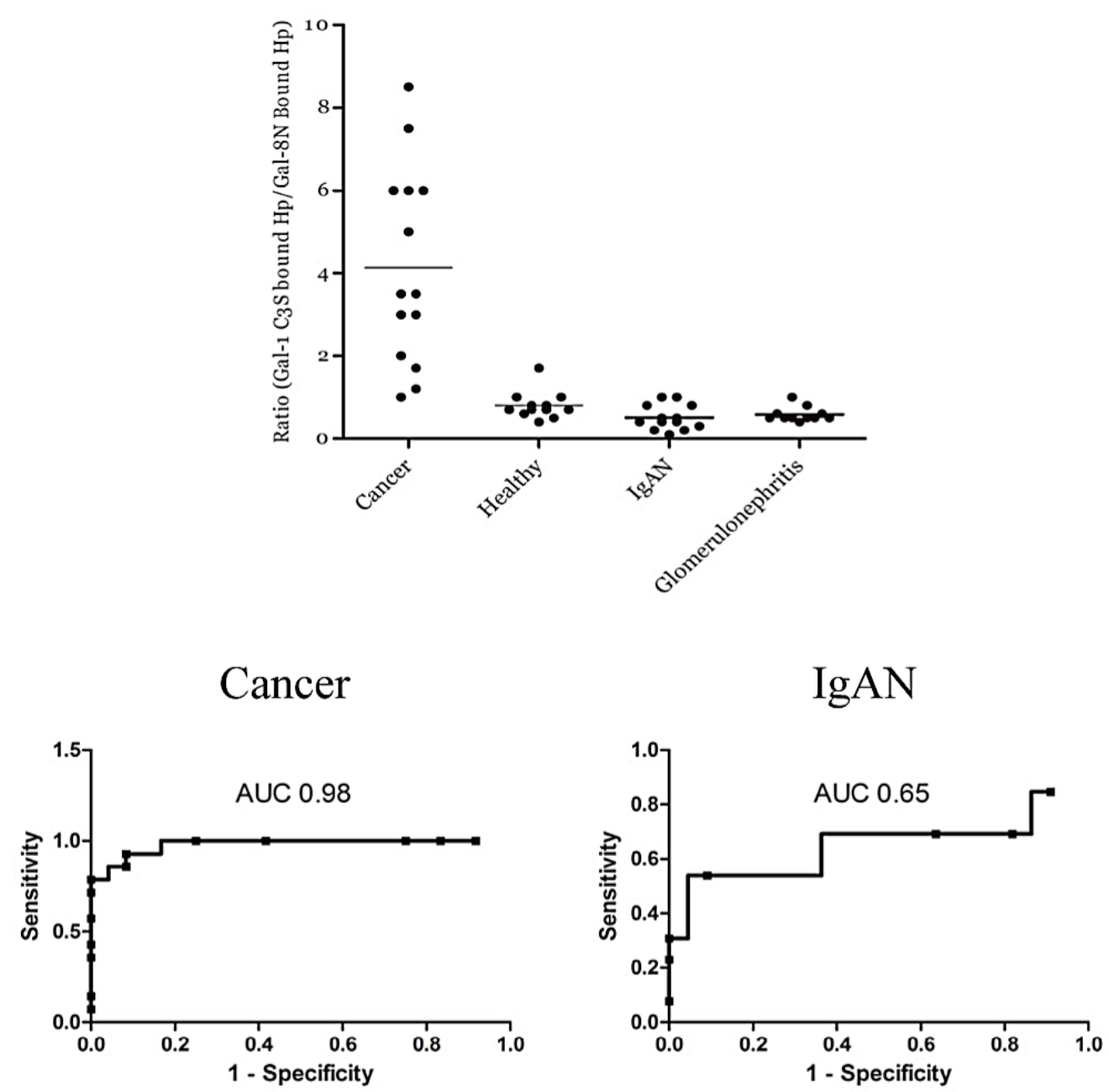